\title{
A identidade corpo-psique na psicologia analítica
}

\section{The body-psyche identity in the analytical psychology}

\author{
Yone Buonaparte d'Arcanchy Nobrega Nasser* \\ Mestre em Psicanálise, Saúde e Sociedade pela Universidade Veiga de Almeida - UVA, \\ Rio de Janeiro, RJ, Brasil
}

\section{RESUMO}

O presente trabalho disserta sobre a identidade corpo-psique através das contribuições que a teoria junguiana traz para a compreensão do tema. Este artigo foi produzido com a intenção de se tornar um material de cunho introdutório para aqueles que desejarem uma iniciação sobre este. Utiliza conceitos fundamentais da psicologia analítica, tais como arquétipo psicóide, complexo e instinto psiquificado. Versa sobre a atualidade dessa teoria, um século após suas fundação, procurando demonstrar seu caminho de acordo com a mudança paradigmática que começava a ser exposta na passagem do século $\mathrm{XIX}$ para o XX. Na verdade, entre outros saberes, mostrou ser um dos expoentes - como a psicanálise - dessa mudança através dos métodos de investigação pelos quais produziram seus conteúdos. A passagem do paradigma da modernidade para o da complexidade - assistido desde então - e o conceito de transdisciplinaridade, apontado por Edgar Morin, foram aqui sublinhados para futuras complementações desse estudo.
\end{abstract}

Palavras-chave: Identidade corpo-psique, Psicologia analítica, Teoria junguiana, Arquétipo psicóide, Instinto psiquificado.

\begin{abstract}
The present paper examines the body-psyche identity through the contribution brought to the theme by the jungian theory. It was produced with the intention of becoming an introductory material for those who wish an initiation on the subject. The article works with fundamental concepts from analytical psychology as psychoid archetype, complex and psychophysical instinct. The author ponders on the actuality of this theory, one century after its foundation, looking to demonstrate that - based in its own references - it has delineated its path accordingly to the change in paradigms that was beginning to be projected in the passage of the XIX century to the XX century. As a matter of fact, among other fields of knowledge - like psychoanalysis - it came to be an exponent of these changes through the investigation methods with which they came to create their contents. The passage of the modern paradigm to the complexity one - seen since then - and the concept of transdisciplinarity, pointed by Edgar Morin, were here underlined to permit future complements for this study.
\end{abstract}

Keywords: Body-psyche identity, Analytical psychology, Jungian theory, Psychoid archetype, Psychophysical instinct. 
O interesse em desenvolver o tema proposto é decorrente de estudos sobre a importância de determinados saberes originados na transição do século XIX para o XX. Entre estes se encontram a psicologia analítica e a psicanálise - ambas colaboradoras para uma mudança na apreensão da relação corpo-psique. Junto a outras tantas disciplinas, apontaram para o início de um afastamento do modelo científico determinista da modernidade. Assim é possível entender a atualidade dessas práticas um século após terem sido fundadas.

Plastino (2003) demonstra a impropriedade dos dualismos que compuseram esse período, dualismos esses que expressavam a separação entre os pares e a supremacia de um sobre o outro. Assim se dava o afastamento entre o homem e a natureza, entre o sujeito e o objeto, entre o corpo e a psique etc.

A partir daí, pode-se entender como o paradigma da modernidade "amarrava", de certa forma, a apreensão e reconhecimento dos saberes que não estavam dimensionados sob as suas regras. Entretanto, esses não deixavam de prosseguir na edificação de um saber que trazia novas possibilidades de entendimento sobre o humano. A psicanálise e a psicologia analítica encontram-se nesta situação epistemológica. Partindo do conceito da existência de um inconsciente substantivo, tornou-se impraticável - para ambas - caminhar sob o referido modelo.

Abre-se, então, a possibilidade de uma re-união dos pares, ponto que compõe parte fundamental do presente artigo.

Para o enfoque de seu delineamento, partiu-se de alguns conceitos essenciais à teoria junguiana, tais como o complexo, o instinto psiquificado e o arquétipo psicóide. Estes conceitos também são essenciais à prática clínica. Há outros, porém, que precisam ser anteriormente desenvolvidos para uma compreensão mais ampla do assunto.

O conceito de psique na psicologia analítica abrange todos os pensamentos, sentimentos e comportamentos, tanto conscientes como inconscientes. É a personalidade do sujeito que se apresenta através de sua psique. "Este conceito sustenta a idéia primordial de Jung de que uma pessoa, em primeiro lugar, é um todo e não apenas uma reunião de partes." (HALL; NORDBY, 1993, p. 25). Esta apreensão colabora para a concepção da identidade corpo-psique.

A psique é composta por vários sistemas e níveis interatuantes. A consciência, um dos níveis, é a única parte que se conhece por sua expressão direta. De modo simplificado, a consciência é orientada por quatro funções básicas: pensamento, sentimento, sensação e intuição. J unto à atitude introvertida ou extrovertida - conceitos relacionados ao

ISSN: $1808-4281$

ESTUDOS E PESQUISAS EM PSICOLOGIA, UERJ, RJ, ANO 10, N.2, P. 325-338, $2^{\circ}$ QUADRIMESTRE DE 2010 http://www.revispsi.uerj.br/v10n2/artigos/pdf/v10n2a03.pdf 
movimento de energia psíquica que possibilita o modo de orientação psicológica - será a combinação de proporções na utilização das funções que fará com que a personalidade básica se diferencie de uma pessoa para outra. É uma atividade funcional cuja dinâmica é sempre constituída pelos opostos complementares, idéia com a qual Jung (1875-1961) trabalha durante toda sua obra: "Nenhuma energia é produzida onde não houver tensão entre os contrários." (JUNG, 1917/1981, § 78).

Para Jung, o ego é o organizador da esfera consciente da psique e é o responsável pelo sentimento de identidade, de continuidade e de coerência.

As manifestações do inconsciente, o contato com sua linguagem riquíssima e variada, e suas significações, são intermediadas pelo ego, propiciando a dialética através do contato com os símbolos - eminentes colaboradores para a compreensão da psique humana. Jung afirma: “Toda a expressão psicológica é um símbolo se pressupormos que declara ou significa algo mais e diferente dela própria, e que escapa ao nosso conhecimento atual. (...)." (JUNG, 1920/1967, p. 543, referente ao $\S 817)$.

Jung, divergentemente da teoria freudiana, não vê a atividade formadora de símbolos intrinsecamente relacionada aos conflitos pessoais, e sim como uma ação mediadora, como uma tentativa de "resolução" entre os opostos - movimento do inconsciente em direção à totalidade.

O símbolo, na concepção junguiana é uma linguagem universal infinitamente rica, capaz de exprimir por meio de imagens muitas coisas que transcendem das problemáticas específicas dos indivíduos (SILVEIRA, 1968, p. 81)

Jung também considera que um símbolo só se mantém vivo enquanto representa a melhor expressão de algo, mantendo-se repleto de significado. Porém, quando seu sentido é esclarecido, ele morre como tal (JUNG, 1920/1967, p. 543, referente ao § 818).

O self - arquétipo central que contempla a ordem, a organização e a unificação assim como o caos, o informe e o virtual - constitui com o ego o eixo ego-self, por onde participa da função transcendente. Esta significa, via de regra, a possibilidade de unir os conteúdos inconscientes e conscientes. O self é referido à totalidade da psique.

Já o inconsciente pessoal é a instância psíquica para onde são enviadas as experiências não cabíveis ao ego - em algum momento - por não se compatibilizarem com a consciência. Entre essas experiências encontram-se conflitos pessoais, morais, situações dolorosas e informações não necessárias no dia-a-dia do sujeito. 
Jung considera que: “(...) É fácil compreender que elementos psicológicos incompatíveis são submetidos à repressão ${ }^{1}$, tornando-se por isso inconscientes; (...)." (JUNG, 1934/1981, § 218).

Sublinha que o inconsciente pessoal, além do material recalcado, contém todos aqueles componentes psíquicos subliminais, que ainda não alcançaram a consciência, inclusive as percepções provenientes dos sentidos. $O$ inconsciente está sempre na tarefa de organizar e reorganizar seus conteúdos (JUNG, 1934/1981, § 218).

Pode-se ter acesso aos conteúdos do inconsciente pessoal - de uma maneira geral - pela formação de constelações, que são reações emocionais associadas. Jung destaca a noção de que não há processos psíquicos nem processos vitais isolados. Eles sempre ocorrem em relação uns com os outros (JUNG, 1934/1991, § 197).

Jung parece trazer a idéia de um enredamento corpo-psique através da compreensão de que os processos considerados vitais - os fisiológicos e os psíquicos fazem parte de uma mesma configuração em suas complexidades operacionais.

Assim, elucidando o conceito de complexo, é importante grifar que este possui energia própria e pode atuar no controle da conduta, sentimentos e pensamentos do sujeito. Segundo Jung, "uma pessoa não tem um complexo: o complexo que a tem". (JUNG, 1934/1991, § 200). Na medida em que os complexos agem inconscientemente, o sujeito tende a ser "levado" por eles.

Torna-se importante relembrar os primórdios dos trabalhos de Jung com - teste de associação de palavras, onde demonstra a natureza psicofísica de alguns complexos que puderam ser mensurados pelo emprego de instrumentos, tais como o galvanômetro, o voltímetro etc: “(...) estas manifestações somáticas do complexo psicológico fazem dele uma entidade pertencente à unidade corpo-mente, e sua presença é demonstrada, experimentalmente, (...)." (BOECHAT, 2004, p. 69). Essas experiências denotam a idéia de uma identidade corpo-psique.

Dessa forma, um dos objetivos do tratamento analítico é auxiliar o sujeito a lidar com seus complexos e propiciar condições para que possa elaborar a autoconsciência e o desenvolvimento de suas potencialidades no intuito de realizar a individuação ao longo de sua vida. Este processo não consiste em um desenvolvimento linear, sendo-Ihe conferido um movimento de circum-ambulação que conduz a um novo patamar psíquico, a um centro - o self, onde é possível realizar a ordenação do consciente e inconsciente em torno deste (SILVEIRA, 1968, p.87), como visto anteriormente. Jung afirma que este é "o meio pelo qual uma pessoa se torna um in-divíduo psicológico, isto é, uma unidade, ou um todo separado e indivisível". (JUNG, 1940/2000, § 490). 
Os complexos, em si mesmos, não são nem "negativos" nem "positivos". São, na verdade, constituintes da psique humana e fonte das emoções. Indicam, dessa forma, que a estrutura psíquica é dotada de uma carga afetiva muito forte, ligando entre si representações, pensamentos e lembranças.

Enquanto Freud (1856-1939) considera os sonhos como a via regia para o inconsciente, Jung confere aos complexos o poder de se traçar este caminho. Sem eles, não teríamos acesso ao inconsciente e este seria composto por representações frágeis e obscuras (JUNG, 1934/1991, § 210).

O efeito negativo de um ou mais complexos, sentido como uma distorção em uma ou mais funções psicológicas - sentimento, pensamento, intuição e sensação - é o que irá caracterizar os sintomas neuróticos, psicóticos e psicossomáticos conforme, entre outros fatores, a relação inconsciente do sujeito com seus próprios complexos.

Em Considerações gerais sobre a teoria dos complexos (1934), J ung une a teoria dos complexos - da primeira fase de sua obra que foi até 1912 com a teoria dos arquétipos e do inconsciente coletivo. Assim, os complexos são sempre vinculados aos arquétipos - como será explicitado mais adiante.

Jung estima que os complexos podem ser agrupados em categorias distintas - complexo mãe, complexo pai, complexo de poder, complexo de inferioridade - e crê que os mesmos repousam sobre bases também típicas, que são os arquétipos. Estes são os alicerces da vida psíquica na teoria junguiana. Completa seu raciocínio esclarecendo que, por trás de suas características pessoais, os complexos possuem conexões com os arquétipos criando uma ponte entre as vivências individuais e as grandes experiências da humanidade. É a relação entre o inconsciente pessoal e o inconsciente coletivo (SILVEIRA, 1968).

Jung concebe o inconsciente coletivo como um nível mais profundo do inconsciente. É um conceito construído embasado em seus estudos sobre fenômenos psicológicos que não podem ser esclarecidos somente a partir da experiência pessoal.

Do mesmo modo que o corpo humano apresenta uma anatomia comum apesar de todas as diferenças (...), a psique também possui um substrato comum. (...) transcende todas as diferenças de cultura e de atitudes conscientes (...). (...) Deste modo, pode ser explicada a analogia, que vai mesmo até a identidade, entre vários temas míticos e símbolos, e a possibilidade de compreensão entre os homens em geral. As múltiplas linhas de desenvolvimento psíquico partem de um tronco comum cujas raízes se perdem muito longe em um passado remoto. (JUNG, 1934/1954 apud SILVEIRA, 1968, p.73)

ISSN: $1808-4281$ 
Em Introdução à psicologia junguiana é bem representada a idéia da identidade corpo-psique - foco do presente artigo - compreendida como uma unidade psicofísica a partir do conceito de inconsciente coletivo.

\begin{abstract}
O conceito de inconsciente coletivo rompe com o determinismo da mente em um sentido estritamente ambiental ${ }^{2}$ e demonstra que a evolução e a hereditariedade dão as linhas de ação para a psique, da forma como o fazem para o corpo. (HALL; NORDBY, 1993, p. 31)
\end{abstract}

Para a questão da identidade corpo-psique, mostra-se importante também relembrar a relação que Jung costura entre os conceitos de arquétipo e de complexo demonstrando ser o primeiro "o núcleo fundamental do complexo, isto é: as imagens arquetípicas coletivas se manifestam na experiência individual pelo complexo psicofísico." (BOECHAT, 2004, p. 50). Dessa maneira, é preponderante o foco que Jung trará, posteriormente, “(...) para a importância clínica do inconsciente coletivo (1912) e de seus conteúdos essenciais, os arquétipos (1919)." (BOECHAT, 2004, p. 48).

O inconsciente coletivo é, em síntese, um reservatório de predisposição à formação de imagens latentes - imagens primordiais - que dizem respeito ao nível mais arcaico da psique e se originam na história e no devir da experiência humana. Quanto mais profunda for a vivência da individuação, maior será o conhecimento dos conteúdos do inconsciente coletivo através de imagens arquetípicas, que são representantes dos arquétipos e as quais se pode ter acesso.

O termo arquétipo vem de arché - origem primeira - significando, então, o modelo original, a imagem primordial. Jung compreende que: “(...). Os instintos e os arquétipos formam conjuntamente o inconsciente coletivo. (...). Chamo-o coletivo porque [é constituído] de conteúdos universais e uniformes onde quer que ocorram." (JUNG, 1919/1991, § 270).

Segundo Jung, os arquétipos resultariam do depósito de impressões deixadas por experiências formadoras e fundamentais comuns à humanidade e que foram repetidas infinitas vezes por milênios, tais como: vivências e fantasias relacionadas à natureza, experiências com a mãe, desafios como a travessia dos mares e montanhas - entre tantas outras (SILVEIRA, 1968, p.77).

Suas investigações e observações levam-no a descrever inúmeros arquétipos referentes a essas vivências coletivas. Há alguns, entre eles, que se tornam mais conhecidos através dos mitos do nascimento, do herói, da morte, de Deus etc. Os arquétipos são pertencentes a todas as 
civilizações e se manifestam nas vivências fundamentais da humanidade enquanto tal.

\begin{abstract}
Entre as ideias representativas dessas vivências encontram-se o nascimento, ligado ao arquétipo da mãe e da criança, como também as transições da puberdade, relacionadas ao arquétipo do herói com seus rituais e desafios. Tem-se o casamento, vinculado à conjunção de opostos (coniunctio), a maturidade representada pelo senex e pelo velho sábio e a realidade identitária profunda ou arquétipo do Self. (JUNG, 1952/1975 apud BOECHAT, 2004, p. 48 e p. 49).
\end{abstract}

Há outros arquétipos considerados indispensáveis na formação da personalidade humana, tais como a persona, o anima e o animus, a sombra e o self - este já configurado anteriormente - que fundamentam a teoria junguiana.

Resumidamente, a persona, termo latino que significa máscara, é basicamente - o arquétipo da conformidade, aquele utilizado na vida social. Em contraposição a este, isto é, como oposto complementar a esta "face externa", Jung destaca os arquétipos referentes à "face interna": anima e animus, representantes psíquicos do feminino e do masculino no homem e na mulher, respectivamente. São compostos a partir da ancestralidade residual das variadas relações entre homens e mulheres. Quando bem integrados, são excelentes mediadores entre o consciente e o inconsciente, auxiliando na capacidade de reflexão e de autoconhecimento.

A sombra pode significar o bem e o mal no ser humano. É, positivamente, responsável pela criatividade, pelas intuições profundas e pela espontaneidade. No lado negativo, estará caracterizada pelas coisas que não são aceitas como pertencentes a si mesmo pelo sujeito e se tornam objetos de projeção sobre o outro - seja este um demônio, um rival, um inimigo ou qualquer outra figura simbólica ou real que possa causar medo, asco etc.

Ao tema central, sobre a identidade corpo-psique, importa demonstrar que os arquétipos são todos - a priori - psicóides. Este conceito psicóide - expressa a conexão substancialmente desconhecida entre o soma e a psique.

Hans Driesch (1867-1941) era biólogo e seus estudos experimentais nessa área acabaram por trazer o interesse pela psicologia e, principalmente, pela filosofia, tornando-se professor dessa disciplina. Criou o termo psicóide para designar "o determinante das reações, o agente elementar descoberto na ação". Bleuler (1857-1939) evoluiu o sentido do termo psicóide definindo-o como a soma de todas as funções mnésicas do corpo e do sistema nervoso, orientadas para um fim, onde 
a psique corporal e a filopsique formavam uma unidade ao qual se empregaria o termo psicóide para designá-la. (BLEULER apud JUNG, 1946/1991, § 368)

Jung vai além e descreve psicóide como um adjetivo que "é aplicável a qualquer tipo de arquétipo, expressando a conexão essencialmente desconhecida, mas passível de experiência, entre a psique e a matéria".(JUNG apud SHARP, 1997, p. 129). I sso significa que todos os arquétipos são, em sua natureza, psicóides - cunhados entre o psíquico e o orgânico, em uma construção de unidade.

\begin{abstract}
Como a psique e a matéria estão encerradas em um só e mesmo mundo, e, além disso, se acham permanentemente em contato entre si, e em última análise, se assentam em fatores irrepresentáveis, há, não só a possibilidade, mas até mesmo uma certa probabilidade de que a matéria e a psique sejam dois aspectos diferentes de uma só e mesma coisa.(...) (JUNG, $1946 / 1991$, § 418)
\end{abstract}

Jung busca, em sua obra, a relação existente entre os arquétipos e os instintos - conceito este que será esclarecido a seguir - demonstrada em seus estudos a partir de 1919. O arquétipo, dessa forma, faria parte dos mundos psíquico e material, sendo psicóide : “(...) o arquétipo ocupa em seus aspectos mais profundos uma posição quase-psíquica e ao mesmo tempo - quase-material, uma posição entre psique e matéria." (BOECHAT, 2004, p. 9).

Mostra-se imprescindível abordar o conceito de instinto em sua apreensão comparativa ao entendimento psicanalítico, já que o mesmo junto ao de pulsão - constitui um aparato teórico para a compreensão da identidade corpo-psique.

$\mathrm{Na}$ psicanálise, o termo instinto indica o esquema quase imutável de conduta herdada por todo sujeito, de forma semelhante ao que ocorre com os animais. Seria uma resposta automática do mesmo nível dos reflexos.

O instinto, de fato, para a psicanálise, difere do conceito de pulsão, sendo este último concebido como “(...) uma força propulsora constituída por impulsos, (...), modificáveis pela experiência, (...) indetermináveis em relação ao comportamento que induzem e ao objeto ao qual se aplicam." (PIERI, 2002, p. 415).

Jung trabalha o conceito de instinto e de que maneira este apresenta uma variação quando relacionado ao ser humano. Por isso, cria o conceito de instinto psiquificado que, como tal, pode - ocasionalmente perder sua característica essencial compulsiva pela modificação forjada no encontro com o dado psíquico. (JUNG, 1937/1991, § 235) 
Sendo o instinto passível de psiquificação torna-se, em parte, uma representação psíquica - e, assim, predisposto a responder de maneira especificamente humana a determinadas situações. Neste sentido, o conceito de arquétipo e o conceito de individuação auxiliam na compreensão de que o aparato psíquico lida com os "impulsos", sejam eles instintos ou pulsões, e que estes apresentam, além de uma base biológica, possibilidades dentro de sua singularidade, onde participam o psíquico e o sócio-cultural.

Em Psicoterapia e visão de mundo, contido em A prática da psicoterapia, Jung delineia o instinto como imbuído de conteúdos arquetípicos. Acredita também que $o$ instinto estimula o pensamento em sua capacidade de livre arbítrio, demonstrando a profunda relação entre corpo e psique, entre o fisiológico e o mental. (JUNG, 1942/2004, § 185).

Na concepção da psicologia analítica, não há uma teoria das pulsões, entretanto os conceitos de instinto e instinto psiquificado - este último considerado como um processo humano - são fundamentais à compreensão do funcionamento corpo-psique: "O instinto como fenômeno psíquico seria (...) uma assimilação do estímulo a uma estrutura psíquica complexa que eu chamo de psiquificação." (JUNG, 1937/1991, § 234).

Para Jung, resumidamente, o instinto é variável e suscetível a diferentes aplicações. Isto significa que a psique se caracteriza por ter a capacidade de transformar-se ou de sofrer variações que causam interferências nos instintos.

Jung identificou cinco principais grupos de fatores instintivos com os quais a humanidade se caracteriza. $O$ primeiro deles é o instinto de autoconservação, relacionado à alimentação. Esta, originalmente ligada ao estado físico nomeado fome - um dos fatores mais primitivos que influenciam o comportamento humano - pode assumir diversos aspectos metafóricos quando combinada a questões de ordem psico-emocional (JUNG, 1937/1991, § 236 e § 237). Quadros de anorexia, de bulimia, de obesidade mórbida e de comportamentos ligados à oralidade em geral e vinculados a variados tipos de prazer e/ou desprazer - são associados a esse instinto. A fome passa a não estar somente associada à alimentação necessária para a autopreservação.Torna-se claro que Jung se remete à possível psiquificação do instinto da fome e, deste modo, reafirma a identidade corpo-psique, na medida em que o corpo mostra ter um funcionamento diversificado em função de sua inexorável parceria psíquica. Boechat esclarece que esse é um dos mais básicos instintos e, ao mesmo tempo, é um dos que propicia mais faculdades simbólicas (BOECHAT, 2008). 
A sexualidade é o segundo instinto que, seguindo de perto o de autoconservação, mostra-se fundamental à continuidade da espécie humana. É um instinto extremamente inclinado à psiquificação, característica que torna possível desviar sua energia biológica para outros canais fornecendo, assim, outras funções e significados peculiares a ele. Um desses canais é tornar a relação sexual prazerosa e proveitosa no escopo do relacionamento humano sem relação direta com a procriação: “(...) As restrições de natureza moral e social que se multiplicam à medida que a cultura se desenvolve fizeram com que a sexualidade se transformasse, pelo menos temporariamente, em supravalor, (...)". (JUNG, 1936/1991, § 238).

Jung denuncia que a sexualidade, tal qual a fome, passa por um processo de psiquificação. Por esse caminho, a energia - de origem instintiva - é utilizada para outros fins que, a principio, lhe são estranhos. Essas observações corroboram a ideia de - no mínimo - uma interação corpo-psique, já que demonstram que as funções humanas, mesmo a princípio consideradas instintivas, denotam um caráter psíquico como algo complementar ao fisiológico.

O terceiro instinto é a atividade, isto é, o impulso à ação. Este é ligado, inicialmente, às lutas necessárias à sobrevivência. Manifesta-se em mudanças, atividades de ímpeto mobilizante etc., incluindo certa dose de agressividade quando necessária.

Já o quarto, a reflexão, representa o impulso religioso e a busca de significado. Deve-se sublinhar que reflexão tem origem em reflexio, que denota o sentido de inclinação para trás e fuga. É possível compreendêlo através da necessidade do ser humano de refugiar-se em si mesmo para encontrar respostas ou mesmo proteger-se da agressividade vigente. Deve haver uma base instintiva que foi transformada pela psiquificação para a vivência humana. Jung entende que a compulsividade é substituída por uma certa liberdade e a previsibilidade por uma relativa imprevisibilidade. (JUNG, 1937/1991, § 241).

O último instinto delimitado é a criatividade e é considerado pertencente a uma classe à parte entre os instintos. Jung não considera que a criatividade seja exatamente um instinto por não se apresentar como um sistema cuja organização costuma ser estável e por não ser comum a todos. Entretanto, percebe que - dinamicamente - ela se comporta como tal. O homem, à semelhança da natureza, é capaz de criar novas coisas e formas. (JUNG, 1937/1991, § 245). O impulso criativo mostrase vinculado a outros instintos - sexualidade, impulso para a atividade e para a reflexão - podendo apresentar um caráter construtivo ou destrutivo em suas conexões com estes.

$\mathrm{Na}$ psicologia analítica, os instintos - em sua característica de 
psiquificação - demonstram ser um aparato teórico suficiente para proporcionar, junto a outros conceitos, o caminho para a compreensão de uma identidade corpo-psique baseada em uma interação entre psique e soma: "(...) Tudo o que se pode afirmar com alguma certeza é que os instintos possuem um aspecto fisiológico e um aspecto psicológico." (JUNG, 1946/1991, § 374).

Torna-se prioritária a noção de que o instinto psiquificado responde à imagem de um corpo-psique que funciona de modo contínuo. Jung faz crer que a psique é fortemente relacionada ao corpo sem, contudo, derivar exclusivamente dele. É apontada uma relação de interação - no sentido de interagir - na identidade proposta. É também apontada uma noção de integração entre corpo e psique que pode ser tratada como unidade (JUNG, 1946/1991).

O pensamento de que corpo e psique possam ser representações distintas de uma mesma identidade é oportuna, na medida em que promove - em primeiro plano - a condição de que não há uma interrupção significante de abordagem, isto é, não há uma cisão entre uma estrutura psíquica e outra corporal. A teoria junguiana permite uma compreensão onde o soma e a psique podem ser entendidos como ambos os aspectos, sob o ponto de vista da observação, de uma mesma matriz. Mais do que isso, pode permitir que se entenda um aspecto de totalidade do psicossoma do sujeito (BOECHAT, 2008).

A partir da apresentação e do desenvolvimento dos conceitos gerais, e em especial, dos conceitos de complexo, arquétipo psicóide e instinto psiquificado, há uma clara demonstração de que corpo e psique estão absolutamente interligados na teoria junguiana, permitindo a concepção de uma identidade corpo-psique. Esta oferece a idéia de uma interação ou de uma integração entre o psíquico e o somático. Desse modo - como duas faces de uma mesma moeda - por um lado, pode ser considerada como dualidade - na noção de interação. Por outro lado, a identidade corpo-psique pode ser admitida como unidade pela integração. Nessa concepção, não se distingue o corpo da psique: um não se constitui sem o outro.

É fundamental que se sublinhe que a psicologia junguiana, dentro de sua práxis, demonstra que sujeito e objeto não constituem pólos opostos. Afirma que a psique é sujeito e objeto ao mesmo tempo observador e observado - quando participante da relação analítica.

Cabe lembrar que a teoria junguiana recebeu grande influência da teoria quântico-relativística - formulada em 1928 - no delineamento e aprimoramento de muitos de seus conceitos. Utiliza, assim, a imagem criada para a luz - que pode ser considerada como onda ou como partícula ao mesmo tempo - em sua formação do conceito de psicóide, 
aplicável aos arquétipos. Na verdade, sempre demonstrou participar de uma visão de compreensão do sujeito mesclado ao seu ambiente. Damião (2002) esclarece como essa relação se desdobra partindo de uma apreciação epistemológica.

\begin{abstract}
Para Jung (1948), a psique e a matéria estão encerradas em um só e mesmo mundo e, além disso, se acham permanentemente em contato entre si e, em última análise, se assentam em fatores transcendentes e irrepresentáveis, a matéria e a psique, que sejam dois aspectos diferentes de uma só e mesma coisa. (DAMIÂO; MELLO, 2002, p.182).

(...)

Será nesse espaço do arquétipo psicóide que haverá o encontro entre subjetividade e objetividade que transcende à psicologia, sendo uma tarefa de todo o processo do conhecimento (DAMIÃO; MELLO, 2002, p.187).
\end{abstract}

Sem dúvida, as proposições trazidas por esse saber o colocam no patamar das mudanças pertencentes à transição paradigmática que se apresenta até os dias atuais. Foge ao foco principal deste artigo, porém mostra-se pertinente sugerir os estudos realizados por Edgar Morin (1996, 2005) sobre essa transição, onde cunha o período que rotula de paradigma da complexidade. Aponta a necessidade vigente de uma convergência - a transdisciplinaridade, isto é, de uma reversão do movimento separatista entre os campos científicos ocorrido durante a modernidade. Por este caminho - da transdisciplinaridade - será permitido aprofundar o conhecimento sobre o humano e desenhar um traçado de ações em prol da saúde psicofísica.

Em síntese, pode-se afirmar que a psicologia analítica - como representante desse novo paradigma - oferece em seus pilares teóricos, o entendimento da relação entre a psique e o soma nos moldes de uma identidade corpo-psique. I sto deve ser considerado de acordo com cada uma das proposições apresentadas: como unidade integrada ou como dualidade interacional.

\title{
Referências Bibliográficas
}

BOECHAT, W. O corpo psicóide: a crise de paradigma e a relação corpo-mente. (146p.) Tese de doutorado em Saúde Coletiva - Instituto de Medicina Social. Universidade do Estado do Rio de Janeiro, Rio de Janeiro, 2004.

. O sonho em pacientes somáticos. Cadernos junguianos. Revista anual da Associação Junguiana do Brasil, vol. 4, p. 19 - 31. São Paulo: Ferrari, Editora e Artes Gráficas, 2008. 
DAMIÃO, M.; MELLO, E. C.C. Reflexões sobre os fundamentos da relação entre matéria e psiquismo: uma abordagem epistemológica da teoria junguiana. Rio de Janeiro: Arquivos Brasileiros de Psicologia, vol.54, ํo 2, p.179-188, 2002.

HALL, C. S.; NORDBY, V. J. I ntrodução à psicologia junguiana. São Paulo: Cultrix, 1993.

JUNG, C. G. Definições (1920). In: Obras completas. Rio de Janeiro: Zahar, 1967. v. 6.

- Tipologia psicológica (1936). In: Obras completas. Rio de Janeiro: Zahar, 1967. v. 6.

- Psicologia do inconsciente. O problema dos tipos de atitude (1917). In: Obras completas. Petrópolis: Vozes, 1981. v. 7.

- O eu e o inconsciente. Inconsciente Pessoal e Inconsciente Coletivo (1934). In: Obras completas. Petrópolis: Vozes, 1981. v.7. . Considerações gerais sobre a teoria dos complexos (1934). In:

Obras completas. Petrópolis: Vozes, 1991. v. 8/2.

. Instinto e inconsciente (1919). In: Obras completas. Petrópolis:

Vozes, 1991. v. 8/2.

. Considerações teóricas sobre a natureza do psíquico (1946/1954).

In: Obras completas. Petrópolis: 1991, v. 8/2.

. Determinantes psicológicos do comportamento humano (1937).

In: Obras completas. Petrópolis: 1991, v. 8/2.

. Instinto e inconsciente (1919). In: Obras completas. Petrópolis: Vozes, 1991. v. 8/2.

- Consciência, inconsciente e individuação (1940). In: Obras completas. Petrópolis: Vozes, 2000. v. 9/1.

. Psicoterapia e visão de mundo (1942). In: Obras completas. Petrópolis: Vozes, 2004. v. 16/1.

MORIN, E. O Pensamento complexo. Rio de Janeiro: Reneo, 1996.

Ciência com consciência. Rio de J aneiro: Bertrand Brasil, 2005.

PIERI, P. F. Dicionário junguiano. São Paulo: Paulus, 2002.

PLASTINO, C. A. O primado da afetividade. A crítica freudiana ao paradigma moderno. Rio de Janeiro: Relume-Dumará, 2001.

O quinto rombo: a psicanálise. In: Conhecimento prudente para uma vida decente. Boaventura de Souza Santos (org.). Lisboa: Afrontamento, 2003. p. 429-460.

SILVEIRA, N. Jung, vida e obra. Rio de Janeiro: José Álvaro Editor, 1968.

SHARP, D. Léxico junguiano. São Paulo: Cultrix, 1997.

Endereço para correspondência

Yone Buonaparte d'Arcanchy Nobrega Nasser 
Universidade Veiga de Almeida, Mestrado em Psicanálise, Saúde e Sociedade, (a/c de Elaine Machado), Rua Ibituruna, no 108, casa 3, CEP 20271-020, Rio de Janeiro - RJ, Brasil

Endereço eletrônico: psi.nasser@terra.com.br

Recebido em: 27/03/2009

Aceito para publicação em: 12/01/2010

Acompanhamento do processo editorial: Adriana Benevides Soares

\section{Notas}

* Membro do LAPSI-UVA, Especialista em Psicossomática pelo IMPSIS; Saúde Mental Infanto-juvenil pela PUC-RJ, e Psicologia Junguiana pelo IBMR/IJRJ .

${ }^{1}$ Os termos repressão e reprimido devem, aqui, ser traduzidos com os mesmos significados que os termos recalque e recalcado, pertencentes à psicanálise. Assim, estão relacionados ao processo inconsciente que exclui da consciência as representações (pensamentos, idéias e imagens) ligadas a uma pulsão cuja satisfação contrasta com outras exigências psíquicas.

${ }^{2} \mathrm{O}$ termo ambiental, no sentido aqui utilizado, tem o significado de empírico. 